\title{
Article \\ The Coordinated Operation of Vertically Structured Power Systems for Electric Vehicle Charge Scheduling
}

\author{
Yuana Adianto ${ }^{1}$, Craig Baguley ${ }^{2, *}$, Udaya Madawala ${ }^{3}$, Nanang Hariyanto ${ }^{1}$, Suwarno Suwarno ${ }^{1}$ (D) \\ and Teguh Kurniawan ${ }^{1}$
}

Citation: Adianto, Y.; Baguley, C.; Madawala, U.; Hariyanto, N.; Suwarno, S.; Kurniawan, T. The Coordinated Operation of Vertically Structured Power Systems for Electric Vehicle Charge Scheduling. Energies 2022, 15, 27. https://doi.org/ $10.3390 /$ en15010027

Academic Editor: Abu-Siada Ahmed

Received: 1 November 2021

Accepted: 13 December 2021

Published: 21 December 2021

Publisher's Note: MDPI stays neutral with regard to jurisdictional claims in published maps and institutional affiliations.

Copyright: (C) 2021 by the authors. Licensee MDPI, Basel, Switzerland. This article is an open access article distributed under the terms and conditions of the Creative Commons Attribution (CC BY) license (https:// creativecommons.org/licenses/by/ $4.0 /)$.
1 School of Electrical Engineering and Informatics, Bandung Institute of Technology, Bandung 40132, Indonesia; yuanaisme@gmail.com (Y.A.); nanang.hariyanto@stei.itb.ac.id (N.H.); suwarno@stei.itb.ac.id (S.S.); teguhrisky@gmail.com (T.K.)

2 Department of Electrical and Electronic Engineering, School of Engineering, Computer and Mathematical Sciences, Faculty of Design and Creative Technologies, Auckland University of Technology, Auckland 1142, New Zealand

3 Department of Electrical, Computer and Software Engineering, Faculty of Engineering, The University of Auckland, Auckland 1023, New Zealand; u.madawala@auckland.ac.nz

* Correspondence: cbaguley@aut.ac.nz

\begin{abstract}
Charge scheduling can mitigate against issues arising from excessive electric vehicle (EV) charging loads and is commonly implemented using time-of-use pricing. A charge scheduling strategy to suit vertically structured power systems without relying on time-of-use pricing has not yet been reported, despite being needed by industry. Therefore, a novel charge scheduling strategy to meet this need is proposed in this paper. Key aspects include the provision of a decision-making framework that accommodates for the considerations of transmission and distribution network operators, and the allowance for dynamically changing charging loads through timely forecast updates with reduced communication requirements. A case study based on the Indonesian Java-Bali power system is undertaken to demonstrate the strategy's effectiveness. Different and realistic EV uptake scenarios are considered, using probabilistic modeling, survey work, and a Monte Carlo modeling approach. Even under slow EV charging conditions case study results show assets are overloaded and high electricity production costs are incurred. These are alleviated through adopting the proposed strategy.
\end{abstract}

Keywords: electric vehicle; Monte Carlo; smart scheduling; particle swarm optimization

\section{Introduction}

Air pollution contributes to $9 \%$ of deaths globally [1]. The electric vehicle (EV) has been promoted as a solution to this problem and many countries around the world have regulated to accelerate EV development. For example, the Indonesian government recently announced government policies and incentives to boost the development of EVs through Presidential Regulation Number 55/2019 [2]. However, and in the absence of a controlled charging strategy, a high uptake of EVs will necessitate significant expenditure on generation, transmission network and distribution network assets.

Strong research efforts have been made on studying the impact of EV charging on different aspects of distribution network performance [3-12], including with demand response control $[13,14]$. In this case, the aim of charge scheduling is to achieve voltage stability and ease the loading levels on distribution network assets, while simultaneously satisfying EV charging demands. However, this approach does not consider electricity production and transportation costs from the energy sources used for generation through to the loads. In this area a body of research has been undertaken, for which the primary application has been microgrid systems. An example is [15]. For such systems, power levels are low, and high-power high voltage transmission networks may not be required. At higher power levels distinct transmission and distribution networks may exist with 
associated transmission system (TSO) and distribution system (DSO) operators. For these power systems, and with regard to charge scheduling, operator coordination is needed.

In certain countries one utility company can control all aspects of power system operation, from generation through to retail, and including the transmission and distribution networks. Such power systems have been defined as having a vertical structure [16], are implemented in countries including China and Indonesia, and have advantages in terms of EV charging information sharing and coordination issues. In comparison to research on the impact of EVs on distribution networks, less research exists on coordinating the actions of a TSO and DSOs for EV charge scheduling purposes. Even less research again exists on TSO and DSO coordination for vertically structured power systems. Coordination can be achieved through centralized charge control, though at the risk of a computation bottleneck forming at the central controller. This is mitigated against through distributed charge control, which assigns the computational burden related to charge scheduling to multiple agents, each of which solves its own small-scale problem [17]. Distributed charge control can be categorized into decentralized schemes that share the computational load across EVs, and hierarchical schemes. As noted in [18], distributed approaches coordinate charging between EVs, but many may neglect to consider network and generation capacity and cost constraints. In these respects, hierarchical schemes, as defined in [17], have greater promise. These delegate control and computational burdens to multiple aggregators, which are defined as intermediaries between the grid and EV users [17]. This naturally suits vertically structured power systems. For countries with such power systems a practical and feasible charge scheduling approach is needed.

Although issues related to coordination between layers are eased for vertically structured power systems, other issues are not. For example, constraints that exist at generation and transmission levels may differ greatly from local distribution network concerns, which vary with EV locations in a distribution network. Therefore, and to allow for concerns at different stages of the electricity production and transportation process, at least two decision-making levels are required. An example of a hierarchical bi-level framework is described in [18], comprising system operator and EV aggregator levels. At the EV aggregator level individual EV charge demands are met, while at the system operator level generation constraints are considered. Bi-level frameworks are also described in [19], and a hierarchical and zonal framework is provided in [20]. This comprises a transmission network, a system operator and multiple distribution networks and EV aggregators. A two (upper and lower) level structure is proposed, with optimization at each level. An allowance is made for generation capacity and transmission line constraints at the upper level, with appropriate charge scheduling handled at a lower level. No allowance is made for distribution network constraints. For each of [18-20], it is not specified how distribution and transmission network constraints are both accommodated for through a decision-making process that fits within the frameworks that are provided. This is an issue, because TSOs are unlikely to have visibility of local distribution network constraints, which may differ for each distribution network. Further, lumping distribution network feeder and transformer constraints into one computational process, as in [18-20] will require significant computational effort for large power systems, because large numbers of these assets will exist. Therefore, any computational benefits realized through using EV aggregators and decentralized charging will be lost.

A very clear framework for a vertically structured power system that comprises station (lowest), municipal and provincial (highest) levels is provided in [16]. By using aggregation techniques at different levels, computational effort and communication requirements are reduced. Real time coordinated charging is provided at station and municipal levels, with day ahead planned charging used at the provincial level. However, the approach described in [16] is critically dependent on time-of-use pricing, which is a convenient mechanism to allow control of charging to be exerted. Examples of other research based on scheduling through pricing strategies, as defined in [17], include [21,22]. 
According to literature, a charge scheduling framework has not been presented for vertically structured power systems that accounts for distribution, transmission, and generation considerations without employing time-of-use pricing, or some other form of pricing strategy. The reliance on employing a pricing strategy can be attributed to its great convenience and effectiveness as a mechanism to control EV charging demand. However, in certain countries it is not available. An example is Indonesia. Accordingly, research in this area is relevant, significant, and needed to solve a key industry issue. Therefore, this paper proposes a novel strategy specifically for vertically structured power systems that is based on charging load prediction obtained from EVs connected to the grid and awaiting charging. It suits the scheduling of slow EV overnight charging that is expected to be predominant in societies with high levels of EV penetration in residential networks, and which will result in peak loading occurring at night times. It does not rely on the existence of complex dynamic electricity price signals to control charging demand, and is specific to vertically structured power systems through taking advantage of the nature of power systems in this form to coordinate DSOs and a TSO in a manner to reduce communication requirements. Clear benefits to the adoption of the proposed strategy include improved system load factors and reduced production costs that are determined under a range of realistic scenarios based on a case study undertaken on the Java-Bali power system in Indonesia. This is a vertically structured power system for which electricity pricing strategies cannot be implemented. Given the significant EV penetration levels that are expected in the near future, the proposed strategy offers a solution to avoid the need for transmission network reinforcement and distribution network upgrades, and supports the acceleration of transportation electrification.

The remainder of the paper is organized as follows. The proposed strategy is described in Section 2. The EV charging load profiles used for the case study are developed for different scenarios and the modeling is described in Section 3, including the EV types in Section 3.2. The scenarios are based on publicly stated aims of government and large private organizations in Indonesia. Case study results in Section 4 demonstrate the effectiveness of the proposed strategy. These results are shown from the perspective of a TSO.

\section{The Proposed Charge Scheduling Framework and Procedure}

The proposed smart scheduling strategy allows for coordination between EVs, DSOs, and a TSO. The DSO collects plug-in time $(t p)$, charge duration time $(t c)$, complete charge time $(t d)$, and State of Charge $(\mathrm{SoC})$ of each EV every half-hour, and sends 12-h predictions of EV load profiles to the TSO. The 12-h time period is chosen to account for the longest possible time an EV will be connected for charging. The TSO collects all DSO EV load profile aggregations and calculates an optimal scheduled load profile using Particle Swarm Optimization (PSO), as well as considering any generation and transmission network capacity constraints that may exist. The generation constraints assure power balance can always be achieved by limiting power demand to be less than generation capacity by a suitable margin. Optimization is in terms of valley filling the power system load profile. The TSO then divides the optimized EV charging load profile between DSOs, and sends the delay time $(t w)$, to each DSO. The delay time is used to schedule the EV charging load and is determined using the PSO algorithm through a fast and reliable computation process. The delay time allows the peak to minimum power system load profile difference to be minimized using peak shaving and valley filling. The DSOs allow EVs to charge based on the EV charging load profile, given and within distribution network asset capacity and voltage constraints. This procedure is repeated every half hour during the scheduling period. The mechanism is shown in Figure 1, with red lines representing communication paths. 


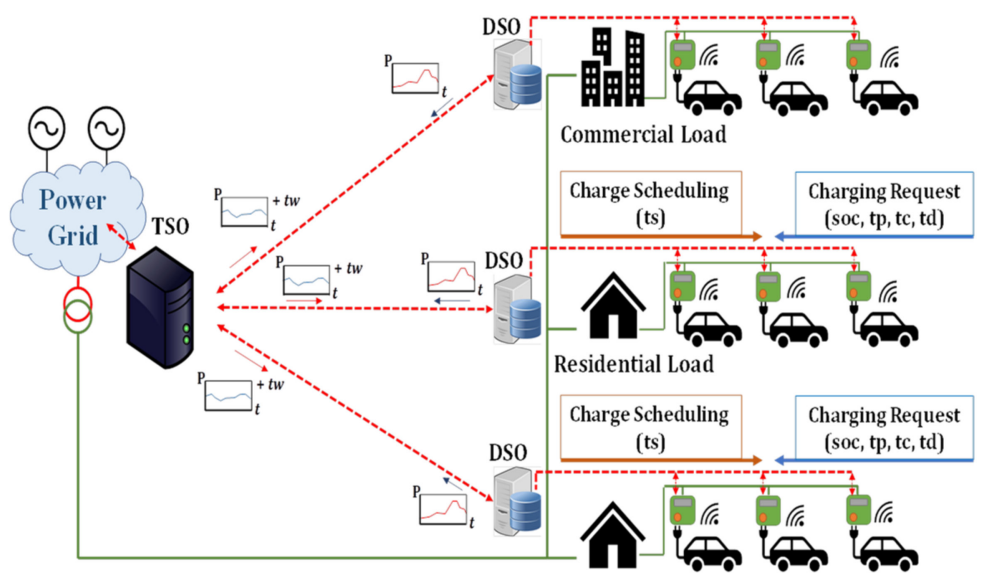

Figure 1. Charge scheduling framework.

The PSO method used is critical for developing real-time, large-scale optimization of the EV charging load allocation schedule. The PSO objective function is to minimize the peak-valley difference $P_{\text {var }}\left(t s_{i, j}\right)$, which is the peak load $\left(P_{\max }\right)$ to minimum load $\left(P_{\min }\right)$, difference of the power system load profile over the time period for which scheduling is applied. This is very important, as high peak loads can stress power system assets through bringing operation closer to ratings, as well as incurring higher operational costs. Start charging time $t s_{i, j}$ is defined as the decision variable, and the objective function is given by:

$$
\underset{t s_{i, j}}{\operatorname{argmin}} P_{\text {var }}\left(t s_{i, j}\right)=P_{\text {max }}\left(t s_{i, j}\right)-P_{\text {min }}\left(t s_{i, j}\right)
$$

where, $i$ represents an EV and $j$ represents the EV type (car, taxi, bus, or motorcycle). The particle position and velocity related to the PSO approach are updated at every iteration, with the next iteration based on the previous computation. The objective function evaluation towards the computation of each particle is defined as fitness. The best fitness of each particle is defined by $p_{k}^{i}$ and the best value among all particles is defined by $p_{k}^{g}$. A flowchart of the PSO approach is shown in Figure 2. For this chart $c_{1}$ and $c_{2}$ are cognitive and social coefficients, respectively, MaxIter is the maximum number of iterations, $w$ is the inertia weight, $v_{k}^{i}$ is the particle $i$ velocity at the $k$ th iteration, and $x_{k}^{i}$ is the particle $i$ position at the $k t h$ iteration.

In this paper, the number of particles (nPop), is 20, MaxIter is 100, $c_{1}$ and $c_{2}$ coefficients are both equal to 2.05, $w$ is 1.0, while $r_{1}$ and $r_{2}$ are random numbers between 0 and 1 . These are applied in (2) and (3) to give:

$$
\begin{gathered}
x_{k+1}^{i}=x_{k}^{i}+v_{k+1}^{i} \\
v_{k+1}^{i}=w v_{k}^{i}+c_{1} r_{1}\left(p_{k}^{i}-x_{k}^{i}\right)+c_{2} r_{2}\left(p_{k}^{g}-x_{k}^{i}\right)
\end{gathered}
$$

In order to avoid an unreasonable increase of velocities, coefficients are restricted to regulate particle velocities. The modified velocities of particles can be represented as:

$$
v_{k+1}^{i}=C_{F}\left[v_{k}^{i}+c_{1} r_{1}\left(p_{k}^{i}-x_{k}^{i}\right)+c_{2} r_{2}\left(p_{k}^{g}-x_{k}^{i}\right)\right]
$$

where,

$$
\begin{gathered}
C_{F}=\frac{2 m}{2-\varphi-\sqrt{\varphi^{2}-4 \varphi}} \\
\varphi=c_{1}+c_{2}>4
\end{gathered}
$$


Generally, $\varphi$ is set to 4.1 where $c_{1}=c_{2}$ and $0 \leq m \leq 1$. This constriction assists the PSO optimization process to converge toward an optimal solution without velocity limitation.

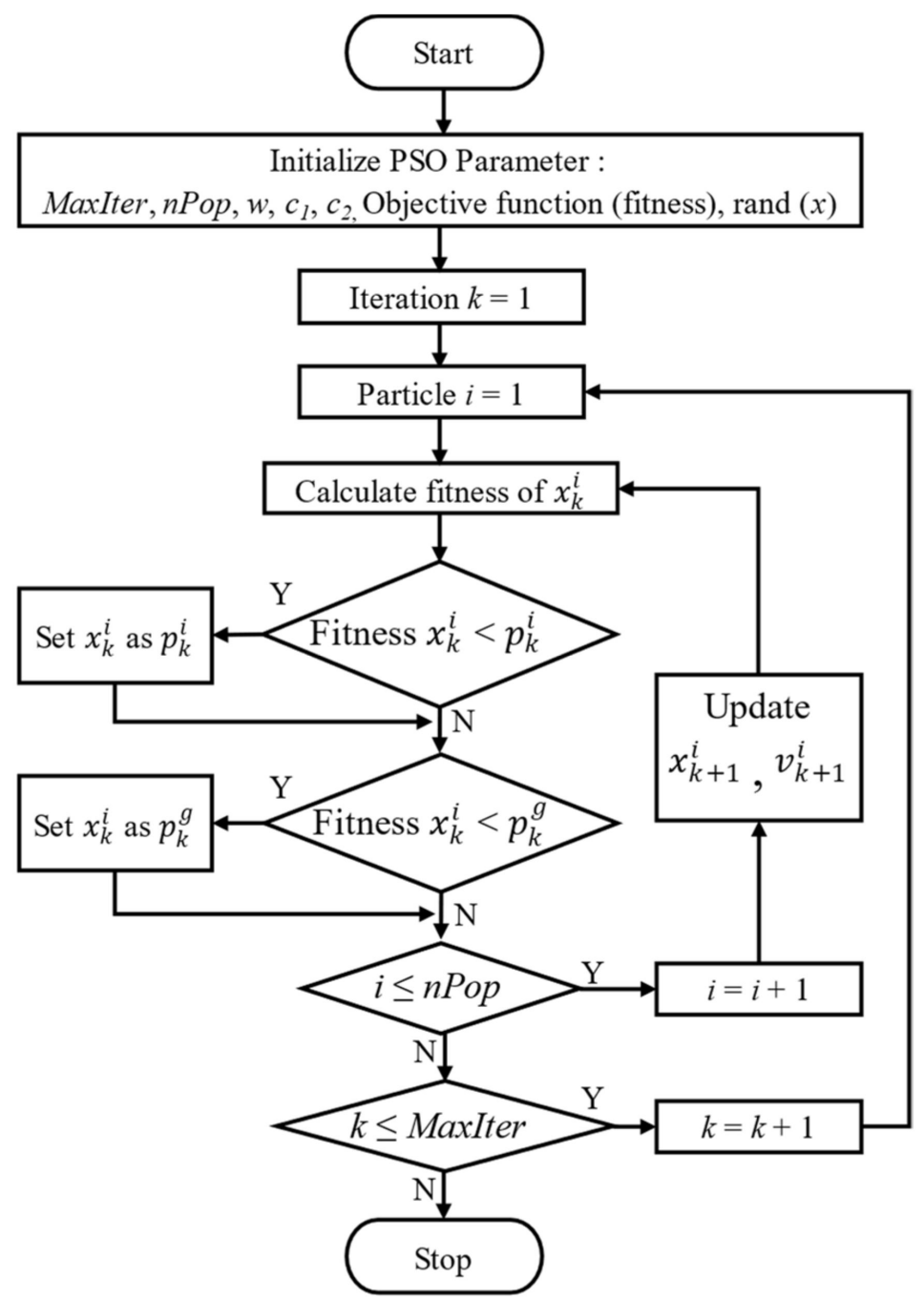

Figure 2. PSO flow chart.

\section{The EV Load Model}

The various EV penetration scenarios are described in this section, along with the vehicle types used for the load modeling. The EV penetration scenarios and types of EVs used for the load modeling are justified based on relevancy to the Indonesian based case study. Charging behavior is then modeled and used to derive charging load profiles.

The EV charging load is modeled using a multivariate probabilistic approach based on Monte-Carlo simulation [23]. EV charging behavior based on survey work is used to improve realism and relevancy. The Monte Carlo simulation and charging demand calculation process is summarized in Figure 3. This incorporates deriving probability density functions of plug-in times, daily mileage, initial SOC, charging duration, and charging mode. These are used to find a daily charging load profile for each EV, before aggregation takes place to determine a charging load profile. 


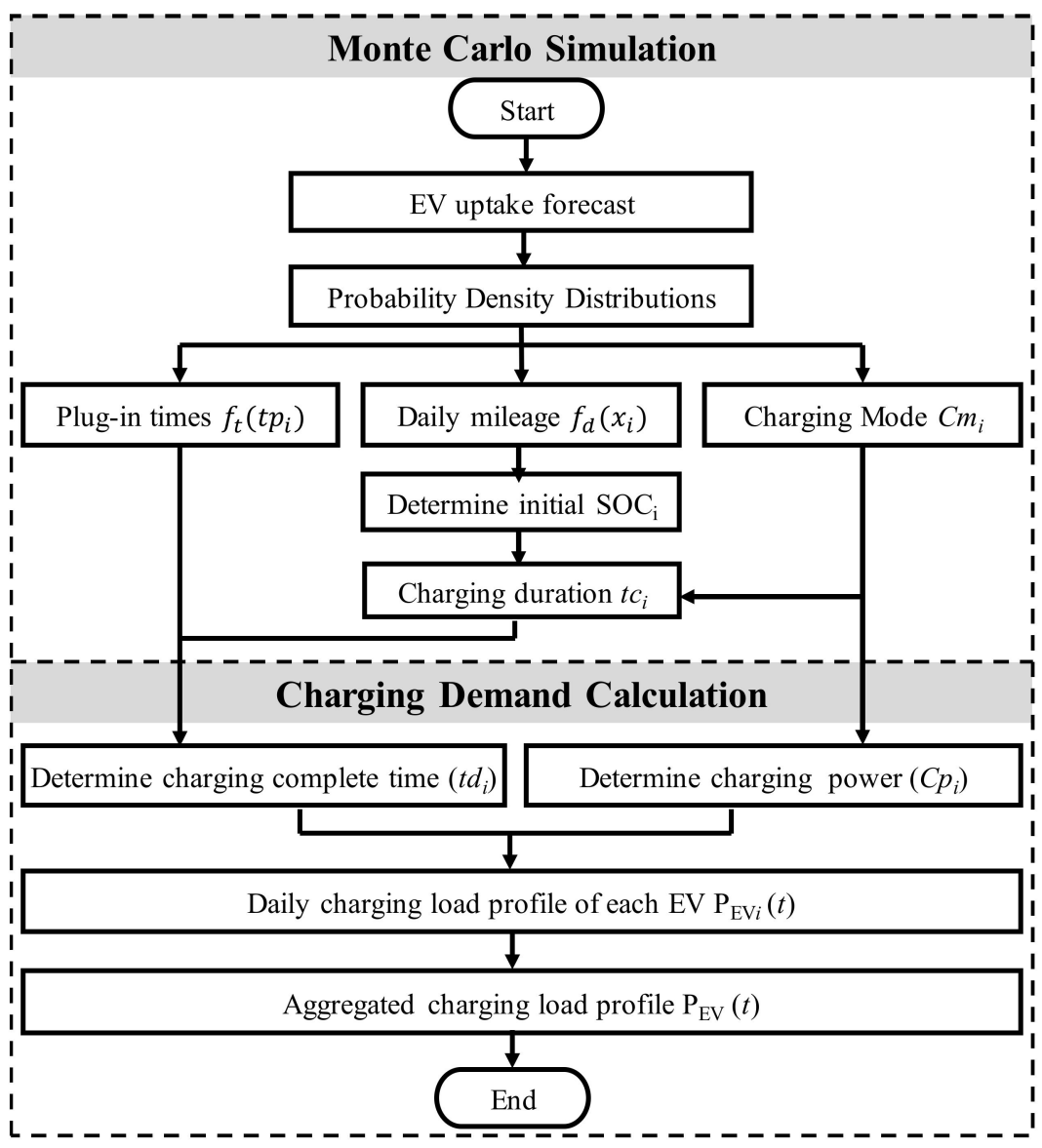

Figure 3. Monte Carlo simulation and EV charging demand calculation.

\subsection{EV Penetration Scenarios}

All EV penetration scenarios considered allow for the targeted utilization of 41,000 electric buses by 2025 by the Transportation Management Agency of Jakarta [24]. By 2025 the stated aim of the largest taxi company in Indonesia is to utilize 2000 electric taxis [25]. Accordingly, electric taxis are allowed for in every scenario. In terms of the private uptake of electric vehicles some variations may exist, including on the vehicle type. Electric motorcycles are expected to dominate EV uptake. This is due to the popularity of this form of transport, as well as the relatively small price gap that exists between electric and internal combustion engine (ICE) motorcycle types [26]. Electric cars are expected to be adopted in lower numbers. However, and in alignment with many other governments, Indonesia plans to stop the production and sale of ICE cars by 2040 , with $20 \%$ of car sales targeted to be electric by 2025 [27].

With knowledge of the targets and aims in Indonesia, four scenarios are developed. These range from low levels of EV uptake in scenario 1, to progressively higher levels up to scenario 4 . Scenarios 3 and 4 are based on EV penetration levels of $15 \%$ and $30 \%$, respectively. For all scenarios the numbers of electric cars are low relative to those of electric motorcycles and in accordance with expectations and the relative popularity of electric motorcycles. In addition, and for all scenarios, the number of electric buses used comprises not only those in Jakarta, but also others in the Java-Bali system and, therefore, exceeds 40,000. The scenarios are listed in Table 1. 
Table 1. Java-Bali EV uptake scenarios.

\begin{tabular}{ccccc}
\hline Scenario & Cars & Motorcycles & Buses & Taxi \\
\hline Scenario 1 & 2200 & $2,168,281$ & 76,540 & 2000 \\
\hline Scenario 2 & 405,352 & $3,794,492$ & 76,540 & 2000 \\
\hline Scenario 3 & $2,444,026$ & $11,933,834$ & 76,540 & 4000 \\
\hline Scenario 4 & $4,888,053$ & $23,867,672$ & 76,540 & 8000 \\
\hline
\end{tabular}

\subsection{EV Types}

The modeling in this paper is based on four different types of EVs. The Tesla model 3 has been sold in Indonesia and was the best-selling electric car in the world in 2019. Therefore, private electric car uptake is based on this EV. Electric motorcycle uptake is based on the Gesits, which is manufactured in Indonesia. Electric bus uptake is based on the BYD K9, as it has been used by the largest bus company in Jakarta. Electric taxi uptake is based on the BYD E6, as this has been used by the largest taxi company in Indonesia. The parameters of these EVs are given in Table 2.

Table 2. Electric vehicle parameters.

\begin{tabular}{|c|c|c|c|c|c|}
\hline \multirow{2}{*}{ EV Types } & \multirow{2}{*}{ Manufacture-Models } & \multirow{2}{*}{$\begin{array}{c}\text { Battery Capacity } \\
\text { (kWh) }\end{array}$} & \multicolumn{2}{|c|}{ Charging Power (kW) } & \multirow{2}{*}{$\begin{array}{c}\text { Mileage Range } \\
(\mathbf{k m})\end{array}$} \\
\hline & & & Slow & Fast & \\
\hline Private Car & Tesla Model 3 & 40 & 2.2 & 45 & 250 \\
\hline Private Motorcycle & Gesits & 2 & 0.55 & - & 50 \\
\hline Buses & BYD K9 & 324 & - & 64 & 250 \\
\hline Taxi & BYD E6 & 80 & - & 32 & 400 \\
\hline
\end{tabular}

\subsection{EV Charging Behavior}

The EV charging needs are determined by random variables including daily travel distance and EV owner driving profiles [28]. A multivariate probabilistic model is used to characterize randomness in the modeling of EV charging demand and is based on survey work and statistics relevant to Indonesia. It is assumed that EV adoption will not make changes to daily travel patterns and daily activity. The uncertainty factors considered when modeling the 24-h EV charging demand are daily travel distance, plug-in time, and EV recharge probability. These uncertainties are defined separately for each EV type which are random variables generated by probability distribution functions (PDF) in Table 3.

The PDFs of EV daily mileage distances are defined to be of either log normal or normal distribution type, as respectively expressed by (7) and (8).

$$
\begin{gathered}
f_{1 d}\left(x_{i, j}\right)=\frac{1}{x_{i, j} \sigma_{d, j} \sqrt{2 \pi}} e^{\left(-\frac{\left(\ln x_{i, j}-\mu_{d, j}\right)^{2}}{2 \sigma_{d, j}{ }^{2}}\right)} \\
f_{2 d}\left(x_{i, j}\right)=\frac{1}{\sigma_{d, j} \sqrt{2 \pi}} e^{-\frac{1}{2}\left(\frac{x_{i, j}-\mu_{d, j}}{\sigma_{d, j}}\right)^{2}}
\end{gathered}
$$

where $x$ represents the daily travel distance of an ith $\mathrm{EV}$, while $j$ represents the EV type $\{j=1,2,3,4\} . \mu_{d}$ are the mean values and $\sigma_{d}$ are the standard deviation values.

$N(\mu, \sigma)$ : Normal probability distribution function

$\log N(\mu, \sigma)$ : Logarithmic probability distribution function

$\mu$ : Mean

$\sigma:$ Standard Deviation

$T p$ : Plug-in time constrain 
Td: Charging complete time constrain

Table 3. Monte Carlo parameters for electric vehicle charging behavior.

\begin{tabular}{|c|c|c|c|c|c|c|c|}
\hline EV Type & $\begin{array}{l}\text { Daily Charging } \\
\text { Frequency }\end{array}$ & $\begin{array}{l}\text { Time Interval } \\
\quad(T p, T d)\end{array}$ & $\begin{array}{l}\text { Charging } \\
\text { Mode (Mc) }\end{array}$ & Prob & $\begin{array}{c}\text { Daily Travel } \\
\text { Distance } \\
\text { Distribution [25] }\end{array}$ & $\begin{array}{c}\text { Plug in Time } \\
(T p) \\
\text { Distribution }\end{array}$ & Remark \\
\hline \multirow{3}{*}{$\begin{array}{l}\text { Private Car } \\
\text { Vehicle }\end{array}$} & \multirow{3}{*}{1} & 07.00-17.00 & Slow & $10 \%$ & \multirow{3}{*}{$\log N(3.47 ; 0.92)$} & $\mathrm{N}(9 ; 0.9)$ & $\begin{array}{c}\text { Charge in } \\
\text { Office }\end{array}$ \\
\hline & & $16.30-07.00$ & Slow & $80 \%$ & & $\mathrm{~N}(18 ; 1)$ & $\begin{array}{l}\text { Charge in } \\
\text { Home/Apt }\end{array}$ \\
\hline & & $07.00-24.00$ & Fast & $10 \%$ & & $\begin{array}{c}\text { Uniform } \\
\text { Distribution }\end{array}$ & $\begin{array}{l}\text { Charge in } \\
\text { Public area }\end{array}$ \\
\hline \multirow{2}{*}{$\begin{array}{l}\text { Private Car } \\
\text { Motorcycle }\end{array}$} & \multirow{2}{*}{1} & 07.00-17.00 & Slow & $20 \%$ & \multirow{2}{*}{$\log N(2.77 ; 0.92)$} & $\mathrm{N}(9 ; 0.9)$ & $\begin{array}{l}\text { Charge in } \\
\text { Office }\end{array}$ \\
\hline & & $16.30-07.00$ & Slow & $80 \%$ & & $\mathrm{~N}(18 ; 1)$ & $\begin{array}{l}\text { Charge in } \\
\text { Home/Apt }\end{array}$ \\
\hline Buses & 1 & $22.00-07.00$ & Fast & $100 \%$ & $\mathrm{~N}(90 ; 10)$ & $\mathrm{N}(22 ; 1)$ & $\begin{array}{l}\text { Charge in } \\
\text { Bus Pool }\end{array}$ \\
\hline \multirow{2}{*}{ Taxi } & \multirow{2}{*}{2} & $20.00-04.00$ & Fast & $100 \%$ & \multirow{2}{*}{$\mathrm{N}(150 ; 40)$} & $\mathrm{N}(22 ; 1)$ & $\begin{array}{l}\text { Charge in } \\
\text { Taxi Pool }\end{array}$ \\
\hline & & $11.00-13.30$ & Fast & $100 \%$ & & $\begin{array}{c}\text { Uniform } \\
\text { Distribution }\end{array}$ & $\begin{array}{l}\text { Charge in } \\
\text { Public area }\end{array}$ \\
\hline
\end{tabular}

The stochastic of daily mileage is obtained from survey work [28], where the mean of daily mileage for private cars, private motorcycles and buses is 30,16 , and $90 \mathrm{~km}$, respectively. Based on [29], the mean value of daily mileage for one taxi shift is $150 \mathrm{~km}$. The EV batteries can only be charged and not discharged, meaning that the energy flow is unidirectional and the vehicle-to-grid concept is not considered.

The State of Charge (SoC) of EV batteries derives from the daily mileage distance and full mileage range of each EV type, and is determined using [23]:

$$
\operatorname{SoC}_{i, j}=1-\frac{d_{i, j}}{D_{j} \times \eta_{1}}
$$

where $d_{i, j}$ represents the daily mileage distance of each EV before charged and $D$ is its full mileage range in $\mathrm{km} . \eta_{1}$ is the battery efficiency, which in this study $\eta_{1}$ is taken as 0.95 .

Plug-in time represents the time the $i$ th EV is connected to power grid and makes a request to charge. The uncertainties of plug-in time are defined separately for each EV which are random variables generated by either normal probability distribution function or uniform distribution. For a normal PDF, the plug-in time is expressed by (10).

$$
f_{t}\left(t p_{i, j}\right)=\frac{1}{\sigma_{t, j} \sqrt{2 \pi}} e^{-\frac{1}{2}\left(\frac{t p_{i, j}-\mu_{t, j}}{\sigma_{t, j}}\right)^{2}}
$$

where $t p_{i, j}$ is plug in time of $i t h \mathrm{EV}, \mu_{t}$ is the mean value, and $\sigma_{t}$ is standard deviation value. For each $\mathrm{EV}$, the corresponding values of $\mu_{t}$ and $\sigma_{t}$ are predefined in Table 3.

After the time of $t p_{i, j}(\mathrm{~h})$, an EV will charge up for $t_{c}(\mathrm{~h})$, the charging duration time. Cap $i, j$ is full battery capacity $(\mathrm{kWh})$ and $P c_{i, j}$ is charging power rate $(\mathrm{kW}) . \eta_{2}$ is charging efficiency assumed as 0.95 . Charging will be finished at $t_{d}$, complete charging time.

$$
\begin{gathered}
t p_{i, j}=\left(1-S o C_{i, j}\right) \times \frac{C a p_{i, j}}{P c_{i, j} \times \eta_{2}} \\
t d_{i, j}=t p_{i, j}+t c_{i, j}
\end{gathered}
$$

The charging demand of all EVs is calculated by aggregating all $\mathrm{EV}$ charging demands, for each 24-h period.

$$
P_{E V i, j}(t)=\left\{\begin{array}{cc}
P c_{i, j} & t_{p} \leq t \leq t_{d} \\
0 & \text { other time }
\end{array}\right.
$$




$$
P_{E V}(t)=\sum_{i=j}^{N_{j}} \sum_{i=1}^{N_{i}} P c_{i, j}(t)
$$

This is added to the base load, $P_{\text {base }}(t)$, which is taken as the original load without any EV charging demands, to derive a total system load profile $P_{T}(t)$ at time $t$ :

$$
P_{T}(t)=P_{\text {base }}(t)+P_{E V}(t)
$$

In this paper uncoordinated charging of EVs is assumed to start immediately upon plug-in, as EV owners are not incentivized to behave to optimize grid utilization. In this case, large-scale EV penetration will add to peak base load demand at times in the evening and, in a worst-case, cause demand to exceed generation capacity. To overcome this problem the smart scheduling approach described in Section 2 is applied and load profiles are compared with, and without the smart scheduling approach. Comparison is also made with a fixed scheduling approach.

The fixed scheduling strategy is applied to private EV cars and motorcycles as, unlike buses and taxis, these have the flexibility to be charged overnight. This scheduling strategy reflects existing policy in Indonesia, where an electricity price discount is given for EV charging after 22:00 [30]. The fixed scheduling period is between 17:30 and 07:00 h (next day). For this strategy, a fixed charging time delay tw of four hours is applied after EV plug-in time. For user convenience considerations, the strategy verifies charging period constraints to assure each EV completes charging before 07:00 (next day).

$$
\begin{gathered}
t s_{i, j}=t p_{i, j}+t w_{i, j} \quad\{j=1,2 \& \text { sched_participation }=\text { True }\} \\
t d_{i, j}=t s_{i, j}+t c_{i, j} \leq 07: 00
\end{gathered}
$$

\section{Simulation Results and Discussion}

The input parameters for each charging strategy simulation in this section were obtained from the Monte Carlo simulation results in Section 3. The targeted EV fleets selected by the proposed charging strategies are private EV cars and motorcycles when they plug into networks between 17:30 and 07:00 h (next day). Electric buses and electric taxis are essential to be fully charged within the shortest time for the next driving work, so these do not participate in the scheduling comparison.

A probability exists that private cars and private motorcycles do not want to participate in the scheduling, in case of emergency or other circumstances. Accordingly, 10\% of EVs are considered not to participate in the scheduling strategies.

From the EV owner point of view, the batteries of the EV have to be charged overnight so the driver can drive off in the morning with a fully charged battery. Therefore, the optimization algorithms aim to achieve peak-shaving and valley-filling effects on the typical daily power curve and, at the same time, assure EV fleets are fully charged before expected usage time 07:00 $\mathrm{h}$ the next day.

Figure 4 shows the modeling of the four different load profile scenarios when EVs are integrated into the Java-Bali power system with uncoordinated charging. The daily energy demand is increased for each EV uptake scenario. The increased energy demand for scenarios 1, 2, 3, and 4 are 11.83, 15.35, 33.22, and 56.54 GWh respectively. As apparent, certain hours show little or no difference between load profiles under the various scenarios. However, peak loads are increased significantly because of the residential charging behavior between 17:30 and 22:00 $\mathrm{h}$.

The increased peak loads after EV integration for the uncoordinated charging scenarios $1,2,3$, and 4 are 333, 861, 4348, and $9298 \mathrm{MW}$, respectively. Scenario 4 shows the peak load can exceed the system generation capacity. Under this scenario it is apparent a scheduling strategy would be required. 


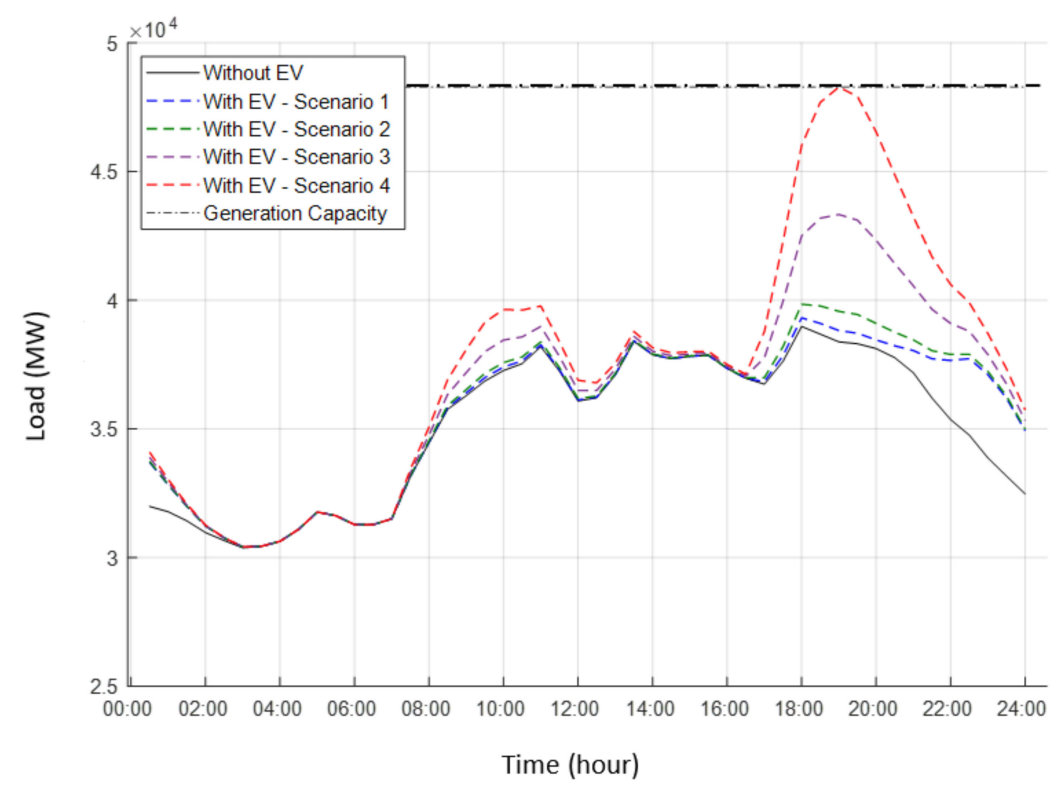

Figure 4. Java-Bali forecasted load profile with various EV integration scenarios with uncoordinated charging.

Java-Bali load profiles without EVs, as well as with scenarios 1 to 4 with fixed charge scheduling applied are shown in Figure 5. The increased peak load after EV integration for scenarios 1, 2, 3, and 4 with fixed charge scheduling are 200, 513, 2092, and $5767 \mathrm{MW}$, respectively. It is apparent that the generation capacity is never exceeded. For scenario 4 , the peak load time changes to 23:00, because bus and taxi charging also takes place at this time.

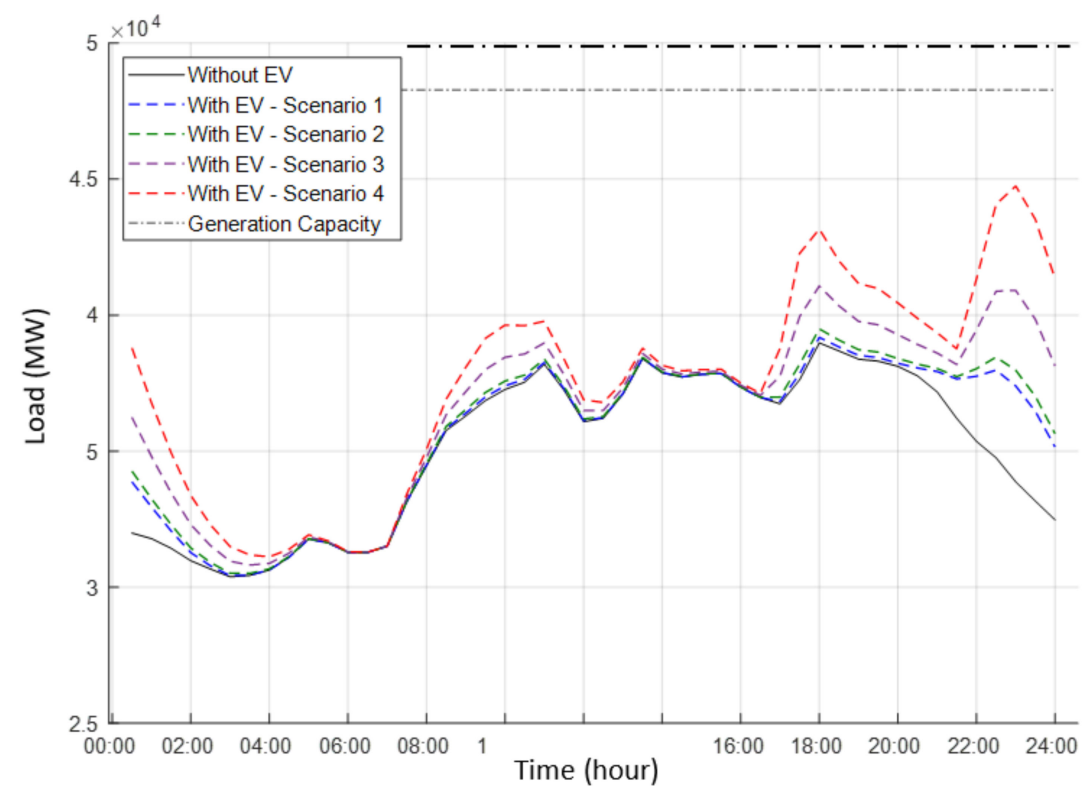

Figure 5. Java-Bali forecasted load profile with various EV integration scenarios with a fixed scheduling strategy.

The Java-Bali load profile without EVs, as well as with scenarios 1-4 with smart scheduling are shown in Figure 6. It is apparent the peak load for scenario 4 is lowered, and the valleys for all scenarios are flattened and improved to some extent. The increased peak loads after scenarios 1-4 and with smart scheduling implemented are 200, 513, 2092, and $4182 \mathrm{MW}$, respectively. 


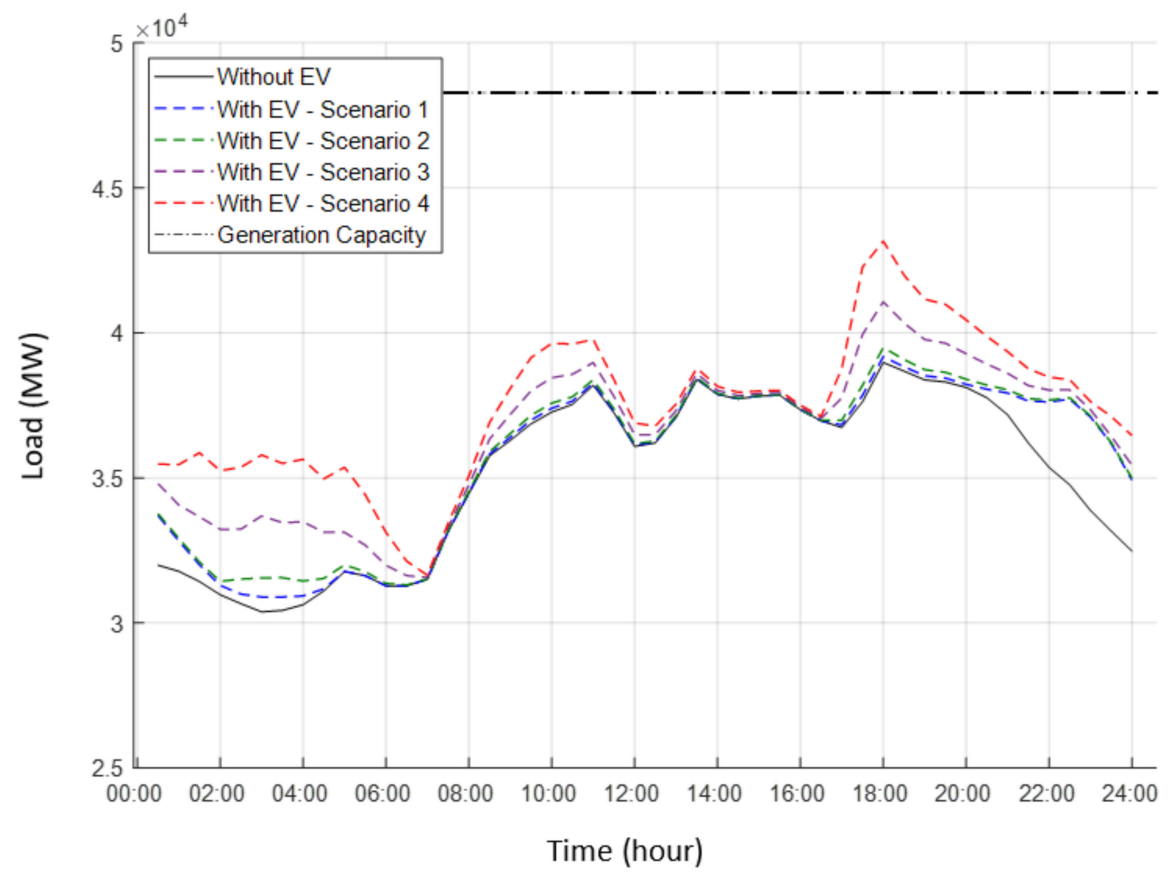

Figure 6. Java-Bali forecasted load profile with various EV integration scenario in smart scheduling strategy.

From the results in Figure 4 it is clearly apparent uncoordinated charging has a significant and undesirable effect on the Java-Bali power system. It is also apparent fixed scheduling and smart scheduling effectively mitigate against high peak loading effects. A summary of the increased peak loads for the EV penetration scenarios considered for the Java-Bali power system are shown in Table 4. Note, fixed and smart scheduling both give the same increased peak load for scenarios 1-3 because EV penetration levels are not sufficiently high to shift the peak load from its maximum at 18:00. For scenario 4 the peak load is shifted due to EV charging loads, as shown in Figure 5, and smart scheduling shows a clear benefit in reducing the peak load level.

Table 4. Increased peak load.

\begin{tabular}{cccc}
\hline Case & Uncoordinated Charging & Fixed Scheduling & Smart Scheduling \\
\hline Scenario 1 & $0.85 \%$ & $0.51 \%$ & $0.51 \%$ \\
\hline Scenario 2 & $2.21 \%$ & $1.32 \%$ & $1.32 \%$ \\
\hline Scenario 3 & $11.15 \%$ & $5.37 \%$ & $5.37 \%$ \\
\hline Scenario 4 & $23.85 \%$ & $14.79 \%$ & $10.73 \%$ \\
\hline
\end{tabular}

Different load profiles will impact on daily load duration probability, as well as power system load factors, defined as the percentage of the system average load to the system peak load. With large-scale EV integration in Java-Bali power system, the load duration probability curves for scenario 4 are shown in Figure 7. As apparent from the uncoordinated EV charging results, the load duration curve is steepened relative to those without EV integration. The smart scheduling strategy results in the flattest load duration curve and, therefore, gives better performance. 


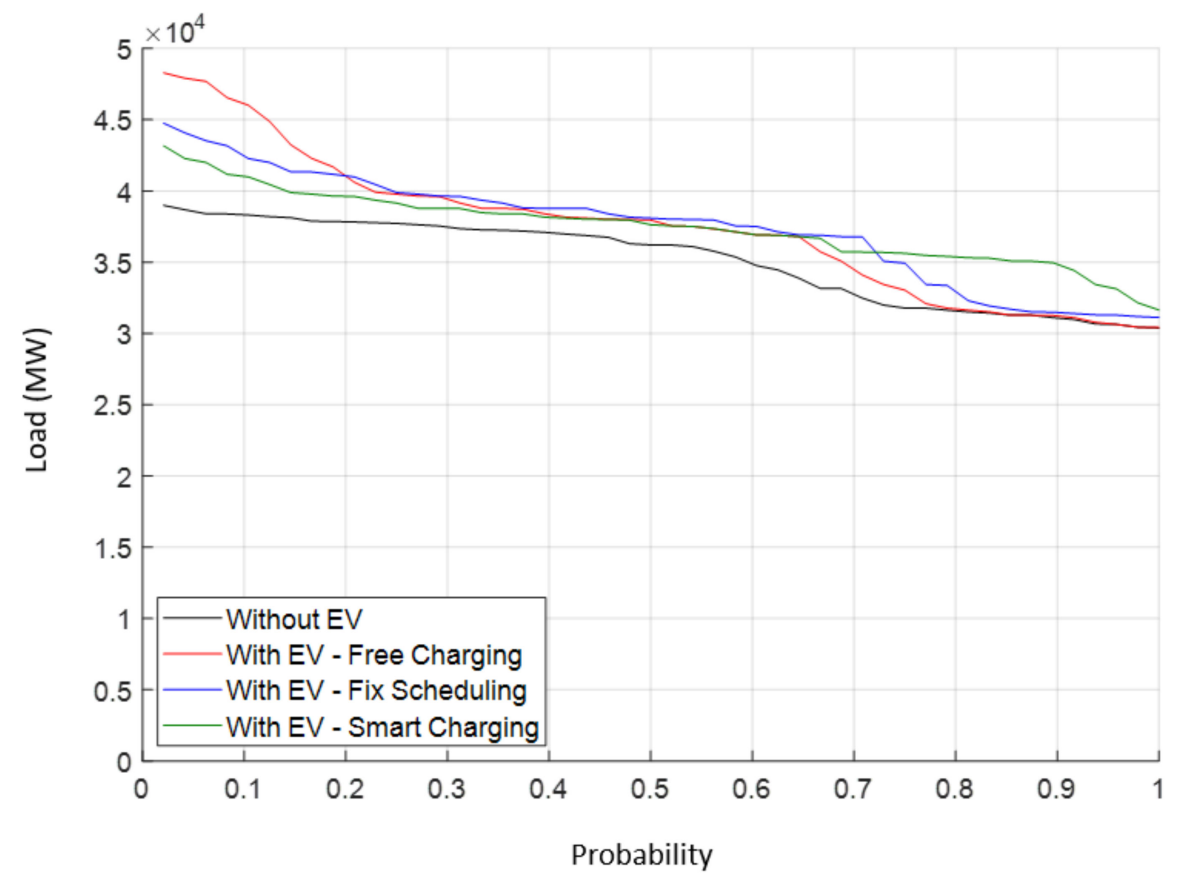

Figure 7. Java-Bali daily load duration probability curve.

The load factor comparison of the EV integration scenarios for uncoordinated, fixed, and smart scheduling charging are shown in Table 5. The uncoordinated charging under scenario 4 results in the worst load factor. Using fixed and smart scheduling strategies will increase the load factor, with the smart scheduling giving best results. Note, because the peak load for scenarios 1-3 is very similar then the load factor for these scenarios is similar. For scenario 4, a clear difference occurs, as the peak load and its time are changed substantially, as shown in Figure 5.

Table 5. Load factor comparison.

\begin{tabular}{cccc}
\hline Case & Uncoordinated Charging & Fixed Scheduling & Smart Scheduling \\
\hline Base & $90.03 \%$ & $90.03 \%$ & $90.03 \%$ \\
\hline Scenario 1 & $90.53 \%$ & $90.83 \%$ & $90.83 \%$ \\
\hline Scenario 2 & $89.69 \%$ & $90.48 \%$ & $90.48 \%$ \\
\hline Scenario 3 & $84.19 \%$ & $88.82 \%$ & $88.82 \%$ \\
\hline Scenario 4 & $77.57 \%$ & $83.70 \%$ & $86.77 \%$ \\
\hline
\end{tabular}

Using the load profile presented in Figures $4-6$ and system data from the electricity utility for Indonesia, electricity production costs can be calculated using Plexos [31]. The calculation combines the fuel cost needed for each power plant type to supply the energy needs in Java-Bali. These power plants are mainly divided into base load and peak load variants, for which the fuel cost of peak load power plants is higher. The increasing load impacts on production costs. This is shown in Figure 8 through spiking of the energy market prices under uncoordinated, fixed scheduling and smart scheduling conditions for scenario 4 . Highest energy market prices are incurred during 17:30 to 22:30 h. Daily total production costs are also affected, and this is shown in Figure 9. The results show the total daily electricity production cost for each scenario, normalized to the cost without any EV penetration. It is again apparent that smart scheduling gives the best results under scenario 4 conditions. 


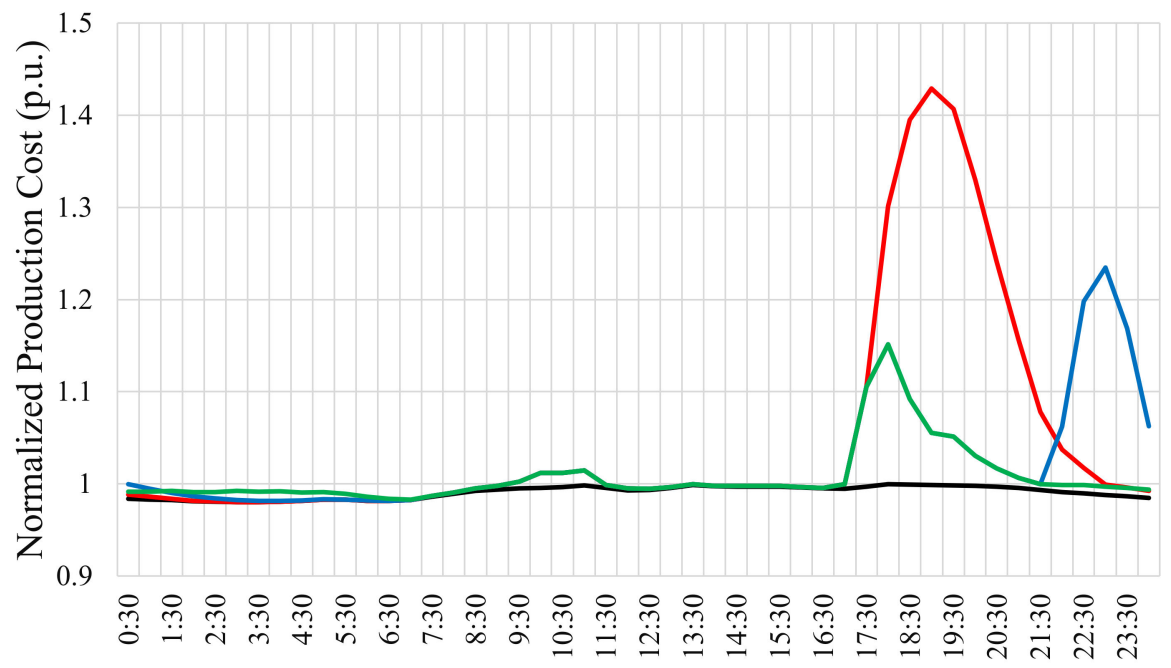

Time (hour:min)

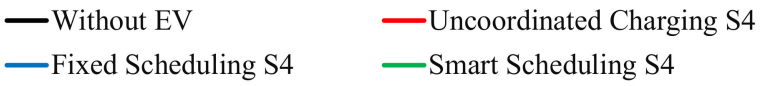

Figure 8. Hourly production cost.

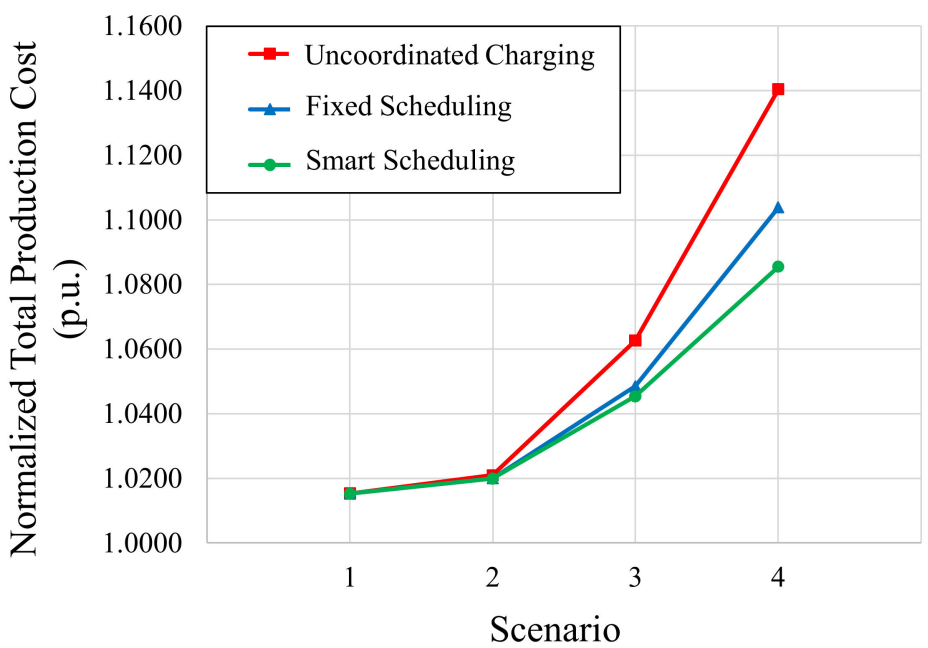

Figure 9. Daily total production cost comparison.

\section{Conclusions}

This paper proposed a strategy that enables vertically structured power systems to mitigate against the impacts of high levels of EV penetration. To demonstrate its effectiveness, the strategy was employed in a case study on the Java-Bali power system for four different scenarios with differing levels of EV penetration. These scenarios are realistic, as public and private industry EV polices were considered, and modeling based on local driving behavior, local vehicle types was employed. The case study results show that for scenario 4, with the highest level of EV penetration at 30\%, the peak load on the Java-Bali power system can exceed the generation capacity. However, mitigation can be most successfully achieved through use of the proposed strategy. The benefits include reducing the peak load by $13 \%$, improving the system load factor by $9.2 \%$, and reducing the estimated production cost by 0.055 p.u. Knowledge of these benefits, as well as those resulting from the postponement of asset upgrades allow for benefits to be compared to the costs of implementing the proposed strategy. This matter is to be addressed. 


\begin{abstract}
Author Contributions: Conceptualization, Y.A., C.B. and U.M.; methodology, Y.A., C.B., U.M. and T.K.; software, Y.A., N.H. and T.K.; validation, Y.A.; formal analysis, Y.A.; investigation, Y.A., C.B., U.M. resources, Y.A., U.M., N.H. and S.S.; data curation, Y.A.; writing-original draft preparation, Y.A. and C.B.; writing-review and editing, C.B. and U.M.; supervision, U.M. and S.S.; project administration, U.M. All authors have read and agreed to the published version of the manuscript.
\end{abstract}

Funding: External funding was provided by PT.PLN (Persero).

Institutional Review Board Statement: Not applicable.

Informed Consent Statement: Not applicable.

Conflicts of Interest: The authors declare no conflict of interest.

\title{
References
}

1. Ritchie, H.; Roser, M. Air Pollution. Our World Data. 2017. Available online: https:/ / ourworldindata.org/air-pollution\#airpollution-is-one-of-the-world-s-leading-risk-factors-for-death (accessed on 27 May 2020).

2. Indonesian Government. Peraturan Presiden Republik Indonesia No 55 Tahun 2019; Ministry of State Secretariat: Jakarta, Indonesia, 2019.

3. Dubey, A.; Santoso, S. Electric Vehicle Charging on Residential Distribution Systems: Impacts and Mitigations. IEEE Access 2015, 3, 1871-1893. [CrossRef]

4. Leou, R.C.; Su, C.L.; Lu, C.N. Stochastic analyses of electric vehicle charging impacts on distribution network. IEEE Trans. Power Syst. 2014, 29, 1055-1063. [CrossRef]

5. Wei, W.; Wu, L.; Wang, J.; Mei, S. Expansion Planning of Urban Electrified Transportation Networks: A Mixed-Integer Convex Programming Approach. IEEE Trans. Transp. Electrif. 2017, 3, 210-224. [CrossRef]

6. Chan, C.; Lu, C.; Lo, Y.L. Optimal Use of Existing Distribution Feeders to Accommodate Transportation Electrification. IEEE Trans. Intell. Transp. Syst. 2015, 16, 1941-1950. [CrossRef]

7. Zhou, B.; Chen, G.; Huang, T.; Song, Q.; Yuan, Y. Planning PEV Fast-Charging Stations Using Data-Driven Distributionally Robust Optimization Approach Based on $\varphi$-Divergence. IEEE Trans. Transp. Electrif. 2020, 6, 170-180. [CrossRef]

8. Morstyn, T.; Crozier, C.; Deakin, M.; McCulloch, M.D. Conic Optimisation for Electric Vehicle Station Smart Charging with Battery Voltage Constraints. IEEE Trans. Transp. Electrif. 2020, 7782, 478-487. [CrossRef]

9. De Cerio Mendaza, I.D.; Szczesny, I.G.; Pillai, J.R.; Bak-Jensen, B. Demand Response Control in Low Voltage Grids for Technical and Commercial Aggregation Services. IEEE Trans. Smart Grid 2016, 7, 2771-2780. [CrossRef]

10. Hu, J.; Si, C.; Lind, M.; Yu, R. Preventing distribution grid congestion by integrating indirect control in a hierarchical electric vehicles' management system. IEEE Trans. Transp. Electrif. 2016, 2, 290-299. [CrossRef]

11. Qi, W.; Xu, Z.; Shen, Z.J.M.; Hu, Z.; Song, Y. Hierarchical coordinated control of plug-in electric vehicles charging in multifamily dwellings. IEEE Trans. Smart Grid 2014, 5, 1465-1474. [CrossRef]

12. Carli, R.; Dotoli, M. A Distributed Control Algorithm for Optimal Charging of Electric Vehicle Fleets with Congestion Management. IFAC-PapersOnLine 2018, 51, 373-378. [CrossRef]

13. Bhattarai, B.P.; Levesque, M.; Bak-Jensen, B.; Pillai, J.R.; Maier, M.; Tipper, D.; Myers, K.S. Design and Cosimulation of Hierarchical Architecture for Demand Response Control and Coordination. IEEE Trans. Ind. Informatics 2016, 13, 1806-1816. [CrossRef]

14. Zhang, L.; Kekatos, V.; Giannakis, G.B. Scalable Electric Vehicle Charging Protocols. IEEE Trans. Power Syst. 2017, 32, 1451-1462. [CrossRef]

15. Chung, H.M.; Li, W.T.; Yuen, C.; Wen, C.K.; Crespi, N. Electric Vehicle Charge Scheduling Mechanism to Maximize Cost Efficiency and User Convenience. IEEE Trans. Smart Grid 2019, 10, 3020-3030. [CrossRef]

16. Xu, Z.; Su, W.; Hu, Z.; Song, Y.; Zhang, H. A hierarchical framework for coordinated charging of plug-in electric vehicles in China. IEEE Trans. Smart Grid 2016, 7, 428-438. [CrossRef]

17. Nimalsiri, N.I.; Mediwaththe, C.P.; Ratnam, E.L.; Shaw, M.; Smith, D.B.; Halgamuge, S.K. A Survey of Algorithms for Distributed Charging Control of Electric Vehicles in Smart Grid. IEEE Trans. Intell. Transp. Syst. 2020, 21, 4497-4515. [CrossRef]

18. Shao, C.; Wang, X.; Wang, X.; Du, C.; Wang, B. Hierarchical Charge Control of Large Populations of EVs. IEEE Trans. Smart Grid 2016, 7, 1147-1155. [CrossRef]

19. Shao, C.; Wang, X.; Shahidehpour, M.; Wang, X.; Wang, B. Partial Decomposition for Distributed Electric Vehicle Charging Control Considering Electric Power Grid Congestion. IEEE Trans. Smart Grid 2017, 8, 75-83. [CrossRef]

20. Yao, W.; Zhao, J.; Wen, F.; Xue, Y.; Ledwich, G. A hierarchical decomposition approach for coordinated dispatch of plug-in electric vehicles. IEEE Trans. Power Syst. 2013, 28, 2768-2778. [CrossRef]

21. Zhang, Y.; You, P.; Cai, L. Optimal Charging Scheduling by Pricing for EV Charging Station With Dual Charging Modes. IEEE Trans. Intell. Transp. Syst. 2019, 20, 3386-3396. [CrossRef]

22. Xu, Z.; Deng, T.; Hu, Z.; Song, Y.; Wang, J. Data-Driven Pricing Strategy for Demand-Side Resource Aggregators. IEEE Trans. Smart Grid 2018, 9, 57-66. [CrossRef]

23. Su, J.; Lie, T.T.; Zamora, R. Modelling of large-scale electric vehicles charging demand: A New Zealand case study. Electr. Power Syst. Res. 2019, 167, 171-182. [CrossRef] 
24. Kompas. BPTJ Targetkan 41.000 Bus Listrik Beroperasi Tahun. 2024. Available online: https://megapolitan.kompas.com/read/ 2019/08/30/07024731/bptj-targetkan-41000-bus-listrik-beroperasi-tahun-2024 (accessed on 3 December 2019).

25. Bluebird Group. Dukung Kelestarian Lingkungan, Bluebird Luncurkan Armada Terbaru Mobil Bertenaga Listrik. 2019. Available online: http:/ / www.bluebirdgroup.com/id/berita/dukung-kelestarian-lingkungan-bluebird-luncurkan-armada-terbaru-mobilbertenaga-listrik/ (accessed on 5 December 2019).

26. Kimura, S.; Suehiro, S.; Doi, N. An Analysis of Alternative Vehicles Potential and Implications for Energy Supply Industries in Indonesia. 2018. Available online: https://www.eria.org/publications/an-analysis-of-alternative-vehicles-potential-andimplications-for-energy-supply-industries-in-indonesia/ (accessed on 25 February 2020).

27. Kemenperin: Payung Hukum Kendaraan Listrik Rampung Tahun Ini. 2019. Available online: https://kemenperin.go.id/artikel/ 20149/Payung-Hukum-Kendaraan-Listrik-Rampung-Tahun-Ini (accessed on 5 March 2020).

28. Indonesia Pathway Calculator. Panduan Pengguna Untuk Sektor Transportasi. 2015. Available online: https: / papua2050.wwf. id/assets/mini_paper/energy/id/PanduanPenggunauntukSektorTransportasi.pdf (accessed on 11 February 2020).

29. Herdianto, R. Berapa Kali Supir Taksi Blue Bird Ngecas Mobil Listrik dalam Sehari? 2019. Available online: https:/ / www.gridoto. $\mathrm{com} / \mathrm{read} / 221818404$ /berapa-kali-supir-taksi-blue-bird-ngecas-mobil-listrik-dalam-sehari (accessed on 27 February 2020).

30. PLN Tawarkan Diskon 30 Persen bagi Pengguna Kendaraan Listrik. Available online: https://money.kompas.com/read/2019/1 2/13/184100026/pln-tawarkan-diskon-30-persen-bagi-pengguna-kendaraan-listrik (accessed on 21 December 2019).

31. Exemplar, E. Features and Benefits-Plexos. Available online: https://energyexemplar.com/plx-features/ (accessed on 29 May 2020). 